\title{
Development of Innovative High-Fashion Collection Via Conceptual Design Process Model
}

\author{
Yu AU and Joe AU* \\ The Hong Kong Polytechnic University, Institute of Textile and Clothing, Hong Kong
}

*Corresponding author: Joe AU, The Hong Kong Polytechnic University, Institute of

Textile and Clothing, Hong Kong.

Received Date: August 23, 2018

Published Date: August 30, 2018

\begin{abstract}
This study aims to demonstrate the creation of an innovative high-fashion collection based on a conceptual fashion design process model. The design process model makes use of understanding the context of design problems, design processes and users in the conceptual design domain. The model is characterized by four phases of design processes, namely investigation, interaction, development and evaluation. Each phase is closely related, connected and interacted with each other. Its focus is on the continuous cyclical design process which can generate an incremental output. By adopting the conceptual design process model, the development of a high-fashion collection is presented in a step-by-step approach. It demonstrates a holistic approach and the orders of importance within the design process, and how it can be rationalized despite the complexities of conceptual fashion design. This experimental activity is meant to provide fashion practitioners with a valuable reference for designing a successful fashion collection in a conceptual context.
\end{abstract}

Keywords: Conceptual; High-fashion; Design process model

\section{Introduction}

Increasing attention has been given to the revolutionary conceptual design in fashion industry. A number of influential designers had stepped out of the commercial side of fashion in reaction to the need for constant renewal. Those designers are characterized as fashion conceptualists. They embrace an innovative approach to fashion in keeping with their personal philosophies and approaches. Their cultural shift, exploration and cross over approaches marked the growing acceptance of fashion as conceptually and culturally significant practice. These fashion conceptualists insist on a holistic approach to their collections, and this includes a key role in originating and overseeing the development of radically novel fabrics and fabric sculptures. Designers such as Hussein Chayalan and Zandra Rhodes are characterized by this fashion dualism.

A systemic view of creativity in fashion and textiles is conducted and four major dimensions namely, "the domain", "the product", "the person", and "the process" are identified. It is important to thoroughly understand the design process, and the emergence and development of conceptual fashion design in order to provide welldeveloped studies as a means to benefit the fashion industry. The fashion practitioners can make reference to the conceptual design process model so as to refine their own creative thinking and design processes.

With the adoption of the conceptual design process model, the creation of an innovative high-fashion collection is demonstrated. The fashion practitioners can better understand the circulation of each stage in the conceptual fashion design process, and the completed systemic process of design within this domain so as to make their designs more successful with a more conceptual, experimental and process-driven approach.

Innovative Conceptual Fashion Design and Its Creative System

A systemic view of creativity in fashion and textiles requires indepth analysis of the following four major dimensions namely, "the domain", "the product", "the person", and "the process".

\section{The domain: the structure of fashion textile design}

Rhodes Ed indicated that the functional criteria (warmth and protection), a desire of change (a psychological drive of the consumer and designer), a desire to make impression (social 
interaction), and strategic commercial interests have shaped the evolution of the fashion industry [1]. The adoption of articles of clothing by consumers as an 'insignia' indicating either their social class or how they wish to be perceived leads to emulation from others [2].

Historically, creative ideas have filtered from the couture houses to the high street. The "trickle-down" theory in fashion explains this social phenomenon in particular. 'High fashion' acts as a creative catalyst and a laboratory for new ideas plays a vital role in the apparel industry [3]. During the 1980s and early 1990s, a proliferation of designers began to source the most innovative fabrics in order to distinguish themselves from the crowd [4]. A new breed of creative professionals took advantage of a slimmed-down, specialized production to target consumers with high-quality, highly symbolic textile products. This explains how the innovative conceptual fashion design was initially formed in the industry.

\section{The product: the creative product that results from the} design processes

McRobbie argued that designers of 'high-fashion' garments generate products that answer two objectives [5]. 'High-fashion' designers create an image of their personal vision, which embodies within the designer label, and is personified by an object, for example, the garment.

Fashion shoots and catwalk shows are opportunities for designers to transmit their creative ideas to an audience and to tempt them to react in some way. All this often portrays the designer's aesthetic, functional, social, and psychological principles that will be adopted by the consumer if they wear the label. The label therefore acts as an 'insignia' which identifies an individual's social grouping. If high-fashion designers wish to promote their labels to a wider consumer base and at the same time increase turnover, then their products have to be diffused into ranges for the mainstream.

High-fashion designers are therefore diversifying into two collections: 1) collection emphasizes the designer's vision and supports the exclusivity of the label 2) diffuses ranges that succeed in generating turnover [6,7]. Diffused ranges have wider popularity at more affordable price ranges and are developed in response to the varying demands of large numbers of customers [8]. This has led to a repositioning of business and to the re-stimulation of the fashion-designer outlet within premier locations around the world [9].

\section{The person: the role of an individual in generating novel fabrics and garments}

Successful high-fashion designers are revered as celebrities for their fresh insights and twists on old ideas [5]. As creative leaders within the fashion domain, high-fashion designers are indeed points of energy within a broader web of activity. McRobbie analyzed the nature of successful individuals in the fashion world are "multiskilled in hand work, design work, publicity and promotions, management, and business and having some idea of manufacture, as well as being in possession of creative vision, imagination, and all the other qualities associated with fashion design" [5].
High-fashion has been referred to as 'idea fashion', and the idea makers have been labelled as fashion conceptualists $[5,10]$. Their works are epitomized by innovation and experimentation. Fashion conceptualists or high-fashion designers are closely associated with artists and craftsmen who are free to generate problems and responses which are important to them. Besides, their work emphasized fine dressmaking and creativity [8]. John Galliano, Alexander McQueen, and Antonio Beradi have prolonged their creativity by placing fashion alongside other art forms.

\section{The process: the methods of generating novel fabrics and garments}

In describing the nature of design, Bruce $\mathrm{M}$ and Rachel $\mathrm{C}$ emphasized that designers "use a combination of intuition, understanding, and current knowledge" to develop design solutions [11]. Concepts are developed via a mix of new information about the domain, for example, technological breakthroughs and the latest marketing information, external stimulus, and previously acquired information.

Hirshberg J described how the antagonism generated by a clash of polarities provides the impetus for the creative spark in design disciplines [12]. Themes based on polarities are common frames of reference for artists and designers, as evidenced by the works of Vivenne Westwood, John Galliano, Jean-Paul Gaultier and Dries van Noten [5].

The fact that combining materials is fundamental to the development of textiles is embodied within the term 'composites', in which "two or more materials, differing in form or composition, are combined to make a new material with enhanced performance characteristics" Braddock SE \& O'Mahony [13]. Experiments in blending wool with copper and silk with stainless steel are leading to exciting new developments in textiles [13].

Many studies indicated that novel fashion and textiles arise from the selection and fusion of elements from diverse sources. Although this mirrors the claims regarding the associative basis of creative processes of an individual described earlier in the study, it fails to provide a framework that describes the nature of product development in the fashion and textiles domain. The existing models of creative processes in other design disciplines tend to illustrate the diversity of the process and provide a broad description of design processes, but there is no specific framework proposed to the conceptual fashion domain.

\section{Development of Collection based on the Conceptual Fashion Design Process Model}

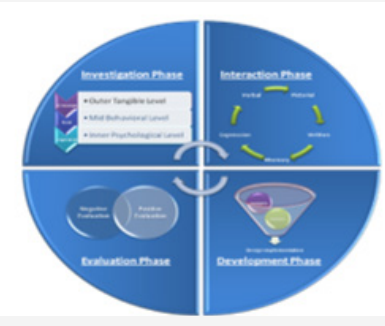

Figure 1: Conceptual fashion design process model. 
An innovative high-fashion collection was designed on the four-phase conceptual fashion design process model, including investigation, interaction, development and evaluation as shown in Figure 1. The four phases are further described as follows:

\section{Investigation phase}

The first phase of the design process model was to identify the key concept in the original objectives and set a scenario that fits three levels: outer tangible level (direction), mid behavioral level (goal), and the inner psychological level (inspiration).

First level: direction: Fashion reflects art, history, culture, sociology, psychology and anthropology. Clothing makes a statement that projects sex, age, class, occupation, origin and personality, as well as what they are or what they want to be at a particular moment. People wear clothes to express their individuality, personality, characteristics and even messages. People sculpt themselves into different forms or structures to represent their creative minds. The fashion conceptual designers have visions and imagination that they live through their garments into the realm of garment making in order to deliver their messages and views.

\section{Second level: goal}

\section{Goal determination}

Each generation encounters several social icons. These icons represent the distinctiveness of an era. They are a symbol and are also used as a projection of one's personality. In this collection, it was inspired by homeless people living on the street. Their odd appearances were used in an in-depth study on the counter-culture bohemia icon and the context of its culture. The investigation of bohemian culture synthesized the similarity with the researcher's background. The uncertainty of social status and cultural background, the instability of lifestyle and the characteristic of freedom was mixed into a distinct statement and displayed in their appearances. Therefore, the researcher's goal was to design an innovative collection which not only had conceptual meaning and distinctive style derived from bohemian culture but was also a witness to a self-determination progress.

Design knowledge : Technically, a bohemian is a person hailing from the provinces of the Czech Republic. Yet the bohemian identity is not created in such specific terms. Rather, it is a collection of daily happenings which are observed and learned from. The idea of Bohemianism emerges from different beliefs and experiences. Bohemia is a region of the Czech Republic, yet the nomadic gypsies are also called "bohemian" by the French. By the mid-1800s, however, French authors such as George Sand and Honoré de Balzac started to use the word 'bohemian' in a very different sense. "One who lives a vagabond, unregimented life without assured a resource, who does not worry about tomorrow" [14]. Although the word was used in this sense since the beginning of the $19^{\text {th }}$ century, not until Murger's play La Vie de Boheme did everyone come to understand the word's new meaning.

Counter-culture movements are an important factor for historical change, and they are usually catalysts for the revolution. Basically, every counter-culture movement in history follows a certain cycle. Beginning to turn the revolutionary movement becomes chic, and some members of the dominant culture may even descend into the counter-culture voluntarily, creating a second generation of the movement. This was the case with the bohemians of $19^{\text {th }}$ century Paris as it was with the Hippies of 1960's America.

The bohemians devoted a lot of time to undermining mainstream culture and they showed their defiance through dress and manners. Bohemian fashion is something of a contradiction in terms because the bohemians usually dressed themselves in whatever they could scrounge up. Bohemian clothing may be anachronistic, distressed, paint streaked, serendipitous, inappropriate for the gender, smocked, embroidered, frayed, fringed, trimmed, shrunken, mismatched, vintage, militaristic, borrowed, custom-made, altered, theatrical, ethnic, folksy, wrinkled, unwashed or new, but it will always be "strangely stylish" [15].

There is no limit to Bohemian ingenuity. Clothing may be dyed, sleeves and collars may be removed or added, and coat linings may be worn as outerwear with a few alterations. Patches, appliqués and fringe may get tacked on, out-of-style accessories may be revived - anything can happen. Alice Prin, the famous Parisian bohemian muse, once cut two Schiaparelli dresses in half lengthwise and sewed the mismatched pieces together. She is also known to have pinned a bit of red dress fabric at the collar of a coat and gone naked underneath. The bohemians are famous, notorious even, for shedding clothing for artistic or mirthful reasons. Contemporary fashion designers often troll the bohemian underworld to glean original ideas, then interpret and sanitize bohemian innovation for the catwalk.

Third level: inspiration: Case studies on contemporary fashion designers and celebrities, such as Anna Sui and Sienna Miller, who are icons of bohemian culture and Boho-chic fashion are conducted. Anna Sui's designs mix styles with time periods. She is influenced by many sources, including classic Chanel suits, Haight-Ashbury hippie chic and glam rock of the 1970s. Sui is a fanatical researcher with an insatiable desire to learn. She draws inspiration from art exhibits, films, flea markets, museums, music and street fashion. She does not simply pluck ideas from the past or another culture, but instead pulls together themes from many sources and seeks to relate them to what people are currently experiencing. Sui wants to express herself through her designs without rules or restrictions. Like all bohemians, she believes in free-thinking and free-living style.

Sienna Miller is the actress who is noted for her fashion sense and often ranks highly in 'best dressed' lists. She is particularly credited for popularizing Boho-chic. Sienna likes to mix designer wear with second-hand vintage wear. Miller made headlines with her clever combination of vintage and designer chic. Her trendy Boho-chic style landed her a contract with top Swedish fashion label "JC jeans And Clothes". Sienna was the obvious choice after she was voted the world's classiest woman by Vogue magazine. She has single-handedly defined the Boho-chic movement and become a style icon.

\section{Interaction phase}

The second phase of the design process model was to develop a concept related to both the designer and his design knowledge. In 
this process, the designer gained in-depth knowledge in relation to the scenario and at the same time was able to relate this knowledge to design problems or requirements. Then the designer was able to appreciate the interaction between the designer's direction, goal and inspiration.

The researcher chose to display the collection in the form of pictorial presentation. The theme and mood boards were displayed for the reasons explained above (Figures 2 \& 3). A solution was proposed at the end of this phase in response to the original objective or requirement suggested. Theme board suggested the stories or concepts that the designer wanted to express in the collection. The researcher's interests and imagination were flooding in the theme board, reflected the spirit of freedom. Colorful content of the theme board also mirrored the researcher's impression to Bohemian culture and lifestyle. Mood board represented a blueprint in the initial stage of design process.

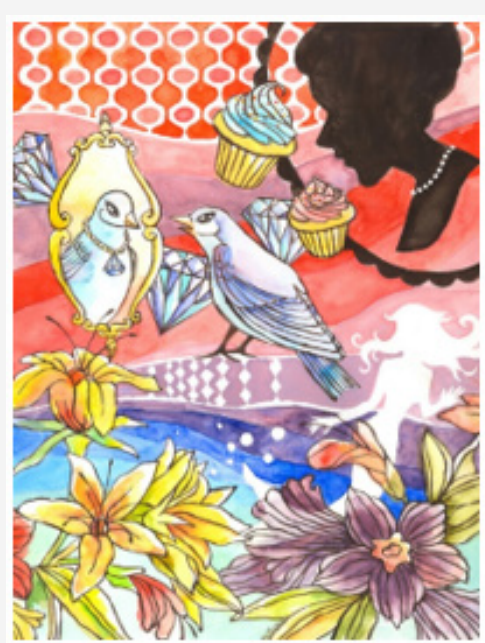

Figure 2: Theme board.

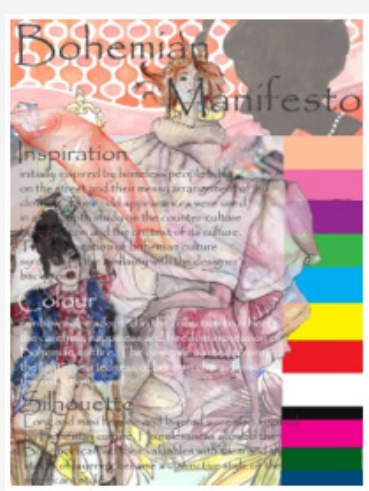

Figure 3: Mood board.

Inspiration: The collection was initially inspired by homeless people living on the street and their messy arrangements of clothing. Their odd appearances were used in an in-depth study on the counter-culture bohemia icon and the context of its culture.

Coloration: Rainbow color was adopted in the collection to reflect the carefree, happiness and freedom impression of Bohemian culture. The researcher wanted to project the feelings of lighter heartedness in the collection through the special usage of colors.
Silhouette: Long to maxi hemline and multi-layers garment construction were also inspired by bohemian culture. Homelessness allowed the Bohemian carried their valuables with them all the time, therefore, stacks of layering became a distinctive style of the significant style.

\section{Development phase}

The third stage of the design process was to develop design sketches including ideas, materials, fabrication, coloration in text and graphics based on the developed concept.

The initial designs were illustrated in rough pencil sketching (Figure 4a) in order to let the designer, have a pictorial idea of silhouette, shapes, formations and details of garments, model postures and color arrangement. The designer had some minor evaluations in this stage of the process. It was a repeated correction when the designer transformed intangible ideas into tangible sketches.

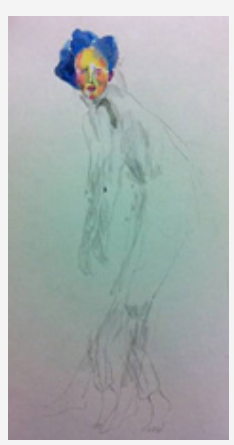

Figure 4a: Example of initial sketch.

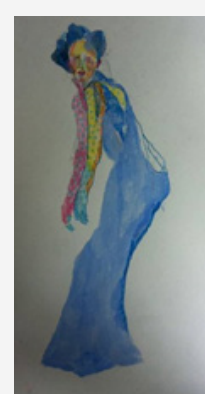

Figure 4b: Example of colored sketch

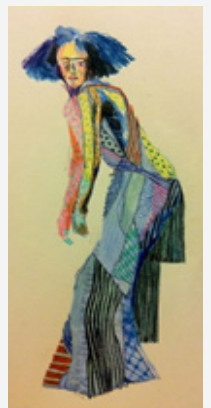

Figure 4c: Example of possible design output.

After confirming the forms, shapes, postures and silhouette of the design, the designer tried out different color arrangements 
(Figure 4b). Possible design outputs were displayed in sketches (Figure 4c). The designer noticed that the repetition of correction and evaluation became less in the later part of sketching. The designer had a greater sense of direction and was confident about the composition of the designs.

\section{Evaluation phase}

At this stage, all conceptual features and deliverable messages from the designer should be listed in a matrix to help the designer to check the conceptual features applied to the design output. In addition, the designer needed to evaluate the features, meanings, aesthetics and appropriateness of the design output in response to the original objective, selected scenario and proposed solution. The designer might make changes to the design output based on the results from the evaluation and implement the prototype and conduct further evaluations or developments.

The researcher used the checklist matrix for evaluation in sequential order. The first checklist summarized the whole concept and scenario of the collection for the designer. The designer could systematically check and write down explanatory notes on the checklist before the evaluation began. The second checklist served as a final inspection before the implementation of design prototypes. This stage involved revolving processes between negative and positive evaluation since the designer might make changes or corrections to the design output based on the results from this evaluation. Consequently, the designer implemented a positive design output or a design prototype and conducted further evaluations.

The next step was to evaluate the design output with the checklist simultaneously. Unlike the first checklist, the designer need not write down ideas and thoughts before evaluation. Instead, the designer used the second checklist to examine the qualification of the design outputs before implementation.

A collection of six design outputs is presented in this section. The collection was introduced in a "story-telling" mode to serve the designer's goal - an innovative design not only had conceptual meaning and distinctive style derived from bohemian culture but was also a witness to a self-determination progress. The design collection was divided into three phases to represent the growing stages and background of the designer.

The immature stage: The design features were derived from the outer level of bohemian culture with material, colour, form, texture, surface, pattern, decoration and details. The outer level features were illustrated by chaotic and disorganized decorations, which were based on the pattern of floral, checks, lines and dots. These chaotic pattern compositions of symbolic meanings could be used as design elements and transferred to innovative textiles.

Childhood memories were similar to a collage of swatches. Pieces of memories were combined like a multi-patchwork of fabric. The designer transformed the proposed concept through garment materials and taking sculpture into the realm of garment. Figures $5 \mathrm{a} \& 5 \mathrm{~b}$ show the two design outputs in the immature stage of the collection.
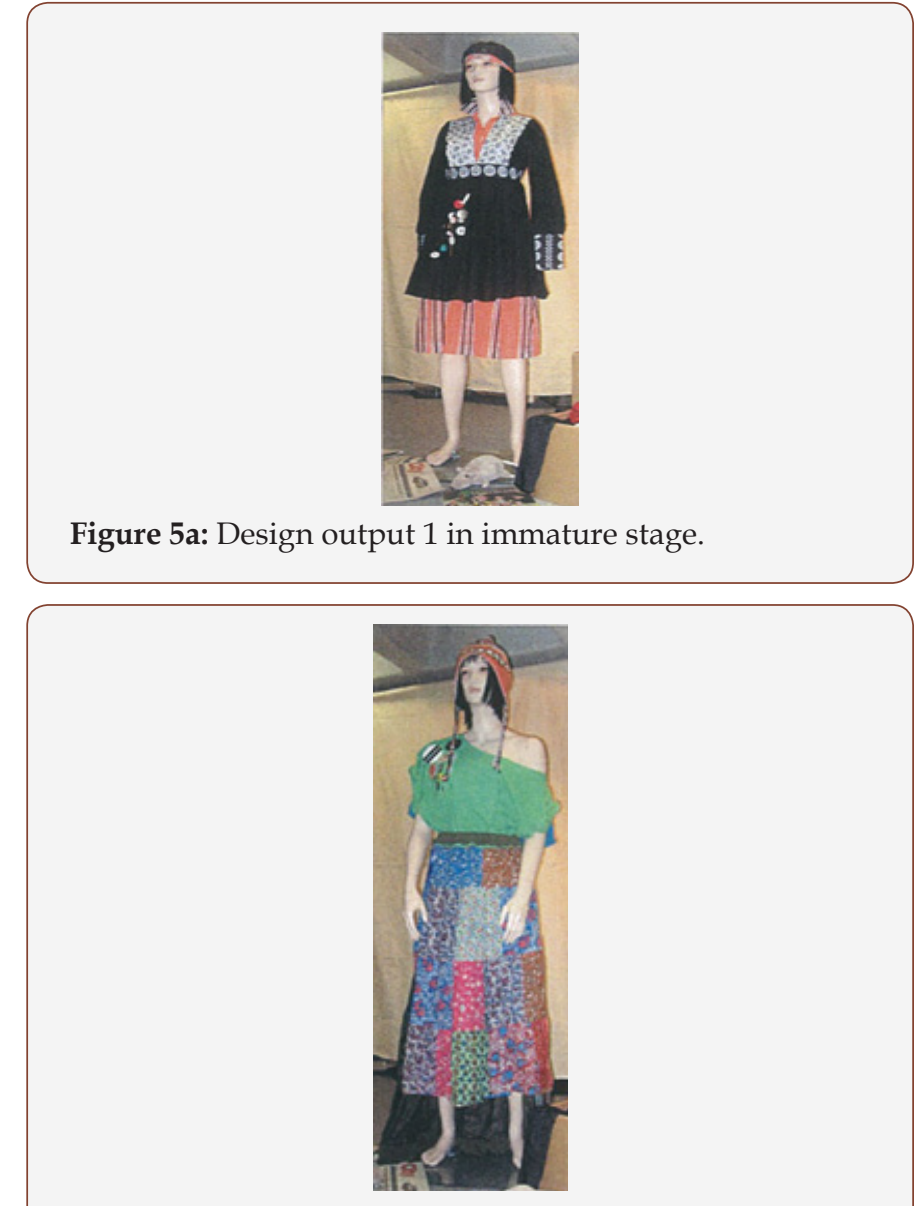

Figure 5b: Design output 2 in immature stage.

The pre-mature stage: The mid level of design features focused on bohemian behavior and the scenarios in which the designer adopted bohemian culture on different occasions in teens. It was noted that bohemian lifestyle was confusing but selfsatisfactory. The patchwork of music, artworks, movies, poems, sculptures reflected a bohemian's everyday lifestyle and culture. "Bohemians felt the need to express and assert themselves at a social and economic disadvantage. It was almost as if they flaunted their marginality by practicing an alternative and contrasting lifestyle - bohemians undermined the bourgeois" [14]. The designer associated the free bohemian style with her teens and created the two design outputs in the premature stage of the collection (Figures $5 c \& 5 d)$.

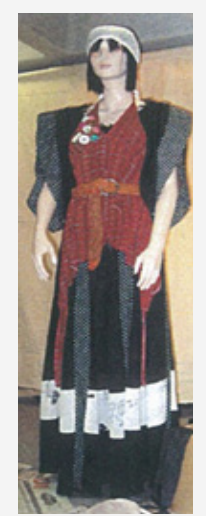

Figure 5c : Design output 1 in premature stage. 


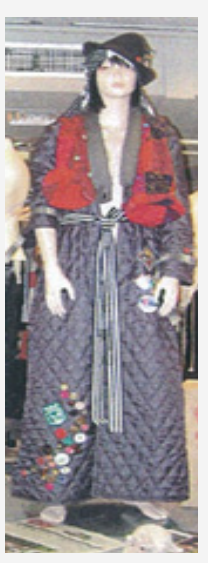

Figure 5d : Design output 2 in premature stage.

The mature stage: This stage was derived from the inner level of bohemian stories and history and focused on the symbolic qualities and their influence on the past century. The present life adventures and experiments in Asia of the researcher have conceptualized into the third stage of the collection. Silhouette and textile compositions became less confusing, which indicated an interface of growth. Figures $5 \mathrm{e}$ and $5 \mathrm{f}$ show the two design outputs in the immature stage of the collection. "Counter-culture movements are an important factor for historical change, and they are usually catalysts for that revolution. Basically, every counterculture movement in history follows a certain cycle. Beginning to turn the revolutionary movement becomes chic, and some members of the dominant culture may even descend into the counter-culture voluntarily, creating a second generation of the movement. This was the case with the bohemians of 19th century Paris as it was with the Hippies of 1960's America, and so on" [14].

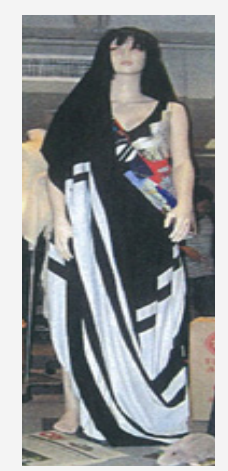

Figure 5e: Design output 1 in mature stage.

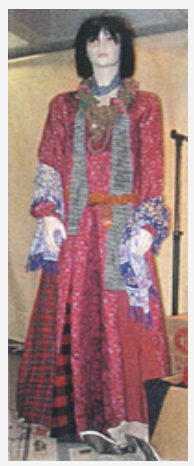

Figure 5f : Design output 2 in mature stage.

\section{Conclusion}

Based on the conceptual design process model, the innovative fashion collection has the four featured phases, 'investigation', 'interaction', 'development' and 'evaluation' discussed in this study. The first investigation phase of the design process model allowed identifying the key concept of the original objectives and to set a scenario that fits three levels included, outer tangible level (direction), mid behavioral level (goal) and inner psychological level (inspiration). The second interaction phase is the concept development and focuses on the synchronization of designers to the developed background from the previous phase. Designers explore all the collected information to synchronize their distinctive ideas and thoughts into tangible information and then to define a margin that has conceptual meaning and style. The instruments that the designers commonly used to display included, pictorial (collages, theme \& mood boards), written (paragraphs, poems), memories (childhood, experiences), expressions (moods, feelings) and verbal (telling stories). The third development phase is the design realization phase. The aim of this phase is to develop a design sketch including ideas and concepts in text or graphics based on the developed background or concept. The developed background or concept may require modification for transforming the conceptual ideas into a logically and technically correspondent output. In the final evaluation phase, the quality of the design outputs is examined before implementation of design prototypes. The bohemian collection provided good examples of conceptual features for design, and yet retained the basic bohemian values with designer's own interpretation for developing innovative highfashion collection.

\section{References}

1. Rhodes Ed (1995) A review of design. Milton Keynes: Open University Press, UK.

2. Hann MA, Jackson KC (1987) Fashion: an interdisciplinary review. J Text Prog 16(4): 1-58.

3. Craik L (1999) Couture shock, Scene, pp. 56-60.

4. Colchester C (2007) Textiles today. Thames and Hudson, London, UK, p. 208.

5. McRobbie A (1998) British fashion design: rag trade or image industry. Psychology Press, London, UK, p. 208.

6. Coleridge N (1988) The fashion conspiracy: a remarkable journey through the empires of fashion. Heinemann, London, UK, p. 323.

7. Hann MA, Jackson KC (1987) Fashion: an interdisciplinary review. J Text Prog 16(4): 1-58.

8. Frings GS (1999) Fashion: from concept to consumer. ( $6^{\text {th }}$ edn), Prentice Hall, New Jersey, USA, p. 376.

9. Moore C, Fernie J (1998) How address sells the dress - examination of fashion designer retailing within London and New York. J Text Inst 89(3): 81-95.

10. Moxey J (2000) The representation of concepts in textile design. J Art and Des Research 9: 50-58.

11. Bruce M, Rachel C (1997) Marketing and design management. Intl Thomson Business Press, London, UK, p. 245.

12. Hirshberg J (1999) The Creative priority: putting innovation to work in your business. Harper Collins, New York, USA, p. 288.

13. Braddock SE, O’Mahony M (2006) Techno textiles 2: Revolutionary fabrics for fashion and design. $2^{\text {nd }}$ Edn, Thames and Hudson, London, UK, p. 208. 
14. Easton M (1964) Artists and writers in Paris: The bohemian idea, 18031867. St Martin's Press, Newyork, USA, p. 205.
15. Stover L (2004) Bohemian manifesto: a field guide to living on the edge: Bohemian Identification. Bulfinch, New York, USA, p. 288. 